\title{
The Relationship between Difficulty in Emotion Regulation and Alexithymia with Hostile attribution bias and Anger in in adolescent boys with high bullying: A Path Analysis
}

majid yousei afrashteh ( $\nabla$ yousefi@znu.ac.ir)

University of Zanjan

parinaz hanifeh

University of Zanjan

\section{Research Article}

Keywords: Difficulty in Emotion Regulation, Alexithymia, hostile attribution bias, bullying, anger, adolescents

Posted Date: February 28th, 2022

DOI: https://doi.org/10.21203/rs.3.rs-1219365/v3

License: (c) (i) This work is licensed under a Creative Commons Attribution 4.0 International License. Read Full License 


\section{Abstract}

Introduction: Adolescence is one of the critical stages and the period of evolution of human physical and mental development that occurs between childhood and youth. Successful completion of this course plays a role in mental health and personality. The aim of this study was to investigate the role of Difficulty in Emotion Regulation and Alexithymia with Hostile attribution bias and Anger in adolescent boys with bullying, which plays an important role in developmental outcomes in adolescents.

Methods: This research was conducted by cross-sectional method. 345 adolescent boys with high bullying living in Zanjan, Iran participated in the study. To measure self-reporting tools, Difficulties in Emotion Regulation Scale (DERS), Toronto Alexithymia Scale (TAS-20), Questionnaire of Hostile attribution bias and State-Trait Anger Expression Inventory tools were used to collect data. Path analysis method was used to analyze the causal model. The results show a good fit of the model with the experimental data.

Results: The results also showed a direct and significant effect between anger with Difficulty in Emotion Regulation $(\beta=0.19, p<0.05)$, with Alexithymia $(\beta=0.17, p<0.05)$ and with Hostile attribution bias ( $\beta$ $=0.32, p<0.05)$ in male adolescents high bullying. As well the mediating role of Hostile attribution bias in the relationship between Difficulties in emotion regulation with anger is significant $(\beta=0.32)$. Moreover the mediating role of Hostile attribution bias in the relationship between Alexithymia with anger is significant $(\beta=0.20)$.

Conclusion: These results contribute to the theoretical knowledge of how Alexithymia and hostile attribution bias affect anger in adolescent populations. The findings supported the mediating role of hostile attribution bias in the relationship between Difficulty in Emotion Regulation and Alexithymia with anger in adolescents. All three predictor variables are trainable and can be used in anger reduction and bullying interventions in adolescents.

\section{Introduction}

Adolescence is a transitional period of development between childhood and adulthood, adolescents are described with unique behaviors $(1,2)$. Adolescence is an important developmental stage that is significant in terms of physical importance, change, and cognitive, behavioral, and social vulnerability, and one of the developmental challenges that occurred during this period(3). One of the common challenges in this period is the phenomenon of bullying, which is especially observed in boys $(1,4)$. Bullying is a widespread public health problem worldwide $(5,6)$. Bullying is an aggressive, intentional, and repetitive behavior committed by a group or individual against one or more victims and usually involves unintended purpose (s) that causes humiliation and distress and can have consequences (7-9). Bullying in general may lead to victimization(10), In addition to being widespread, bullying is associated with a number of negative consequences, including depression(6). 
Anger is an unpleasant state that is often defined as a negative emotional response to perceived stimulation $(11,12)$. In addition to paying more attention to negative details, anger also causes bias in information processing $(11,13)$. Anger is a strong stimulus for aggressive actions(14) Which increases aggression mainly through purposeful manipulation or threatening of interpersonal relationships $(15,16)$ includes harm, violation of other rights, theft and bullying(17).

The important point is that negative stimuli do not naturally produce anger, but Cognitive processes such as evaluation, expectations, and private speech also interfere. (18). Aggressive people tend to describe the motives of others as vague and provocative rather than harmful or accidental. This tendency is called hostile attribution bias $(19,20)$. Identifying and recognizing negative situations and correctly assessing the intentions of individuals play a decisive role(21) that indirect biases against the existence of such siding reduce the social performance of adolescents(19) This bias is more used in the period of adolescent development (16).

Health literacy is defined as the knowledge and competence of individuals to successfully manage emotions $(22,23)$. The difficulty is the most important aspect of emotion regulation. Difficulty in Emotion Regulation includes lack of awareness, Not accepting emotions, and dysfunctional and ineffective behavioral responses(24). Emotion regulation is a meta-diagnostic structure that is a special form of selfcontrol and resulting from experience (24-26).

Another variable in the transition from thought to anger is Alexithymia, which comes from a Greek word meaning lack of a word to describe emotion, Was invented by sifneos in 1972 (27) Which refers to a disorder in the identification and expression of emotions $(28,29)$ Which has shown a weak communication(30) And it consists of two aspects, cognitive and emotional(31,32). Alexithymia is characterized by disturbances in emotional regulation(33). Alexithymia is a psychological trait, not only is there Difficulty in Emotion Regulation, but there is also a defect in the cognitive processing of emotions, so emotions remain indistinguishable $(29,30,34,35)$. Lan(36) states about people with Alexithymia that these people express emotional distress through physical complaints(35). Which is characterized by difficulties in identifying and describing their emotional state and is associated with deficits in empathy and emotional awareness. It also affects social functioning and can be associated with problems in reflecting mental states(37), Ellis(38) showed Alexithymia was positively associated with aggression in students, Also in Conway(39) research Children who have negative emotions and have difficulty in emotion regulation are more likely than other children to engage in aggressive behaviors, On the other hand, according to the results of Van Bockstaele et al(20), the Hostile attribution bias can be targeted by using training techniques, and such changes in training bias may reduce aggression in adolescents, In this regard, the results of the study Xua, Chen and Xia(40) argued that child abuse may cause immediate aggression during a provocative event through Hostile attribution bias and lead to delayed aggression after interpersonal conflict through ruminant Be angry.

Adolescent disorders can be one of the strongest predictors of depression, substance abuse, and dropping out of college in adulthood. According to the existing studies, the relationship between the 
Hostile attribution bias in adults and university students has been considered and studied. While the aim of this study was to investigate the relationship between difficulty in emotion regulation and alexithymia with hostile attribution bias and anger in in adolescent boys with high bullying.

\section{Methods}

The present study wants to investigate the relationship between difficulty in emotion regulation and alexithymia with hostile attribution bias and anger its method is cross-sectional, specifically path analysis.

\section{Participants}

The participants were includes adolescents aged 12 to 18 years in Zanjan, Iran 2021. Using Cochran's formula, the sample size was estimated to be 345 . The inclusion criteria included informed consent and confidentiality of the questionnaires online without mentioning the name, being a teenager, and exclusion criteria for the research were distorted and incomplete questionnaires. The convenience sampling was used to select the sample. Recruitment occurred from February 1 th to April 10th 2021. Out of 345 participants in this study, 35 (10\%) were 12 years old, 38 (11\%) were 13 years old, 47 (13\%) were 14 years old, 55 (15\%) were 15 years old, 49 (14\%) 16 years old, 61 people (17\%) are 17 years old, 60 people (17\%) are 18 years old. More details are reported in Table 1.

Table 1. Demographic characteristics of the subjects 


\begin{tabular}{|lll|}
\hline Variable & Number & Percentage \\
\hline Age & & \\
\hline 12 & 35 & 10 \\
\hline 13 & 38 & 11 \\
\hline 14 & 47 & 13 \\
\hline 15 & 55 & 15 \\
\hline 16 & 49 & 14 \\
\hline 17 & 61 & 17 \\
\hline 18 & 60 & 17 \\
\hline Educational status & & \\
\hline Student & 280 & 81 \\
\hline Dropout & 65 & 18 \\
\hline Mother's education & & \\
\hline Reading and writing & 108 & 31 \\
\hline Secondary & 163 & 47 \\
\hline University & 74 & 21 \\
\hline Father's education & & 24 \\
\hline Reading and writing & 90 & 26 \\
\hline Secondary & 171 & 49 \\
\hline University & 84 & 24 \\
\hline Number of children & & \\
\hline 1 & 101 & 29 \\
\hline 2 & 56 & 24 \\
\hline 3 & & \\
\hline 4 & & \\
\hline
\end{tabular}

\section{Procedure}

This is a cross-sectional study and was done in several steps. The first step was performed with the aim of identifying students with high bullying in a sample of 1150 people. Participants completed the Illinois Bullying Scale. In the next phase, participants who had a high bullying score in the first phase were asked to participate in the second phase. 345 of these people participated in the second stage. In this phase, 
participants completed four Difficulties in Emotion Regulation Scale, Toronto Alexithymia Scale, Questionnaire of Hostile attribution bias and State-Trait Anger Expression Inventory-2 ${ }^{\text {TM }}$ Child and Adolescent (STAXI-2 ${ }^{\text {TM }} \mathrm{C} / \mathrm{A}$ ). All rights of the participants were protected during this study. All procedures performed in study involving human participants were according to the ethical standards of the National Research Committee. The executive process of this research has been approved by the Ethics Committee of Kermanshah University of Medical Sciences under No. IR.KUMS.REC.1400.608.

\section{Instruments}

\section{Difficulties in Emotion Regulation Scale (DERS)}

This scale was developed in 2004 by Gertz and Roemer(41) to assess the difficulty in emotion regulation, which has 36 items and 6 dimensions (Nonacceptance of Emotional Responses, Difficulties Engaging in Goal-Directed Behavior, Impulse Control Difficulties, Lack of Emotional Awareness, Limited Access to Emotion Regulation Strategies and Lack of Emotional Clarity). each of the items of this scale in the 5point Likert From very rare to almost always is arranged and the minimum and maximum scores are 36 and 180, respectively. The results indicate that this scale has good internal consistency and Cronbach's alpha was obtained above 0.80 in Gertz and Roemer research(41). Based on research conducted by Pandey, Saxena and Dubai(31), the Cronbach's alpha of this scale was 0.90. Also, in Ghasemi, Beyrami and Vahedi(42) research, the reliability of the test through Cronbach's alpha for the whole test was 0.95 , which is a very desirable value. The reliability of DERS in the present study was obtained with Cronbach's alpha coefficient of 0.77 .

\section{Toronto Alexithymia Scale (TAS-20)}

Toronto Alexithymia Scale (TAS-20) was developed by Taylor, Ryan and Bagby(43) and has three subscales (Difficulty in recognizing emotions, difficulty in emotion regulation and objective thinking) and 20 items. The items to score based on a five-point Likert scale from a score of 1 for "strongly disagree" to 5 for "strongly agree". The minimum and maximum scores are 20 and 100, respectively. And Cronbach's alpha coefficient in Chen, $\mathrm{Xu}$, Chen and Chang(44) research for the whole scale was 0.83 , test-retest reliability coefficient was 0.87 and the correlation of the three factor coefficients with the total scale score was from 0.72 to 0.82 Also, in Ghorbani and Bagheri(45) research, the reliability of the whole instrument by Cronbach's alpha method was 0.82 . The reliability of TAS-20 in the present study was obtained with Cronbach's alpha coefficient of 0.75 .

\section{Questionnaire of Hostile attribution bias}

$\mathrm{HAB}$ was measured using the SIP-ABQ, which was rated on a 4- point Likert scale from not at all likely (0) to very likely (3). The English language questionnaire was translated into Chinese and then backtranslated by three bilingual speakers. This questionnaire consisted of eight vignettes. Each vignette described an ambiguous social situation followed by four questions that assess direct Hostile attribution bias (e.g., 'The club members wanted to ignore me'), indirect Hostile attribution bias (e.g., 'The club 
members wanted me to feel unimportant'), instrumental nonhostile intent (e.g., 'The club members were more interested in talking among themselves'), and benign intent (e.g., 'The club members didn't hear me say " $\mathrm{Hi}^{\prime \prime}$ ). The sum scores of the 16 items that assess direct and indirect Hostile attribution bias represent the degree of HAB Coccaro et al(46) The alpha reliability in the sample was good $(a=0.89)$ and In the research of Wang et al(47) Cronbach's alpha in the was 0.88 at Time 1 and 0.91 at Time 2.

\section{State-Trait Anger Expression Inventory}

The present questionnaire is taken from STAXI-2, which was designed by Spielberger (1) in 1988 to measure anger in adults. In this research, the Persian version of STAXI-2 C / A has been used to measure the experience, expression and control of anger in children and adolescents. In this research, the Persian version (STAXI-2 C / A) has been used In Heidari Nasab, Barabadi and Moghaddasin(49) research, Cronbach's alpha coefficient for State of anger and trait of anger was obtained from 0.94 to 0.88 . The Cronbach's alpha coefficient for the clinical group on the anger scale scale was 0.94 , the anger trait was 0.88 , the outward anger was 0.84 , the inward anger was 0.74 , and the anger control was 0.89 . The results show that this tool has a good reputation. In the Persian version, seven factors of feeling anger, verbal and physical expression of anger, angry temperament, and angry reaction, expressing anger outward, expressing anger inward and controlling anger were identified. Brunner and Spielberger(48) reported a Cronbach's alpha coefficient of 0.74 for the whole test, 0.87 in State of anger and trait of anger, 0.70 in outward anger, 0.71 inward anger, and 0.79 in anger control. In the present study, the reliability of this instrument was obtained with Cronbach's alpha coefficient for seven Persian scale factors of $0.70,0.73$, and $0.79 .0 .72,0.85,0.80$, and 0.72 respectively.

\section{Statistical analysis}

To analyze the data, descriptive statistical indices including mean and standard deviation as well as Pearson correlation coefficient and path analysis were used to test the hypotheses. The analysis was conducted with SPSS v.26 (IBM), and LISREL v10.2. Due to the high sample size, the normality is less important(50) Despite this, the skew index for the research variables was between -1 to +1 , which indicates that the distribution of variables is normal. Therefore, there was no limit to the use of Pearson correlation coefficient and path analysis with LISREL software. Path analysis with ordinal data was conducted using the diagonally weighted least squares method (WLSMV). We examined the hypothesized model using all data obtained by the original questionnaire. The model fit indices were Chi square statistics, Chi square/df, Root Mean Square Error of Approximation (RMSEA), Comparative Fit Index (CFI), Tucker-Lewis Index [TLI, also known as the Non-normed fit index (NNFI)], Goodness of Fit Index (AGFI) and Adjusted Goodness of Fit Index (AGFI). The model was judged as having good fit when the overall picture of fit indices indicated good fit and excellent if all of them indicated well fit: RMSEA $\leq$ $0.05, \mathrm{CFI}$ and $\mathrm{TLI} \geq 0.95$, and WRMR $<0.90$ (51).

\section{Results}


Descriptive statistics including mean and standard deviation as well as correlation matrix for the relationship between variables are reported in Table 1.

Table 2: Descriptive statistics and correlation matrix

\begin{tabular}{|llllll|}
\hline Variable & Average & Standard deviation & 1 & 2 & 3 \\
\hline 1.Difficulty in regulating emotion & 121.33 & 24.41 & - & - & - \\
\hline 2. Alexithymia & 69.29 & 10.96 & $0.17^{\star \star}$ & $0.31^{\star \star}$ & $0.36^{\star \star}$ \\
\hline 3. Hostile attribution bias & 65.02 & 11.18 & $0.26^{\star \star}$ & $0.19 \star \star$ & \\
\hline 4. Anger & 104.32 & 18.35 & $0.29 * \star$ & & \\
\hline
\end{tabular}

According to Table 2, all Pearson correlation coefficients are significant for the relationship between variables $(P<0.05)$. The correlation between anger and difficulty in emotion regulation is 0.29 , with Alexithymia is 0.19 and with the Hostile attribution bias is 0.36 . The correlation between difficulty in emotion regulation and Difficulty in Emotion Regulation and Hostile attribution bias is 0.17 and 0.26 , respectively.

Table 3. Path coefficients for direct, indirect and total effect of Difficulties in emotion regulation, Alexithymia and Hostile attribution bias on anger Psychological well-being 


\begin{tabular}{|c|c|c|c|}
\hline Path & $\begin{array}{l}\text { Standard } \\
\text { parameter }\end{array}$ & $\begin{array}{l}\text { t- } \\
\text { value }\end{array}$ & $\begin{array}{l}\mathrm{P}- \\
\text { value }\end{array}$ \\
\hline \multicolumn{4}{|l|}{ Direct effect } \\
\hline Difficulties in emotion regulation (DER) $\rightarrow$ Anger & 0.22 & 3.45 & $P<0.01$ \\
\hline Alexithymia $\rightarrow$ Anger & 0.20 & 3.37 & $P<0.01$ \\
\hline Hostile attribution bias $(\mathrm{HAB}) \rightarrow$ Anger & 0.32 & 8.23 & $P<0.01$ \\
\hline $\begin{array}{l}\text { Difficulties in emotion regulation }(D E R) \rightarrow \text { Hostile attribution } \\
\text { bias }(H A B)\end{array}$ & 0.17 & 4.98 & $P<0.01$ \\
\hline Alexithymia $\rightarrow$ Hostile attribution bias (HAB) & 0.17 & 2.86 & $P<0.01$ \\
\hline \multicolumn{4}{|l|}{ Indirect effect } \\
\hline $\begin{array}{l}\text { Difficulties in emotion regulation (DER) } \rightarrow \text { Hostile attribution } \\
\text { bias }(H A B) \rightarrow \text { Anger }\end{array}$ & 0.06 & 2.14 & $P<0.01$ \\
\hline Alexithymia $\rightarrow$ Hostile attribution bias $(\mathrm{HAB}) \rightarrow$ Anger & 0.07 & 2.27 & $P<0.01$ \\
\hline \multicolumn{4}{|l|}{ Total effect } \\
\hline $\begin{array}{l}\text { Difficulties in emotion regulation (DER) } \rightarrow \mathrm{HAB} \rightarrow \\
\text { Anger }\end{array}$ & 0.28 & 6.29 & $P<0.01$ \\
\hline Alexithymia $\rightarrow$ Hostile attribution bias $(\mathrm{HAB}) \rightarrow$ Anger & 0.27 & 3.02 & $\mathrm{P}<0.01$ \\
\hline
\end{tabular}

Table 3 shows the direct, indirect, and total effects for the relationship of the variables in the model. According to the results of this table, Difficulties in emotion regulation $(\beta=0.22)$, Alexithymia $(\beta=0.20)$, Hostile attribution bias $(\beta=0.32)$ have a significant direct effect in the variance of anger. According to the results of table 3 , the mediating role of Hostile attribution bias in the relationship between Difficulties in emotion regulation with anger is significant $(\beta=0.32)$. Moreover the mediating role of Hostile attribution bias in the relationship between Alexithymia with anger is significant $(\beta=0.27)$.

In Figure 1, the standard parameter and the value of $\mathrm{t}$ are reported.

The model fit indices are reported in Table 3.

Table 4: Model fit indices 


\begin{tabular}{|llll|}
\hline Indicator & amount & Desirable level & Condition \\
\hline $\mathrm{X} 2$ & 4.22 & - & - \\
\hline $\mathrm{df}$ & 3 & - & - \\
$\mathrm{P}$ & 0.002 & $>0.05$ & Undesirable \\
\hline $\mathrm{X} 2 / \mathrm{df}$ & 1.41 & $<3$ & Optimal \\
\hline $\mathrm{RMSEA}$ & 0.04 & $<0.05$ & Optimal \\
\hline $\mathrm{GFI}$ & 0.96 & $>0.90$ & Optimal \\
$\mathrm{AGFI}$ & 0.96 & $>0.90$ & Optimal \\
\hline $\mathrm{TLI}$ & 0.97 & $>0.90$ & Optimal \\
\hline $\mathrm{NFI}$ & 0.95 & $>0.90$ & Optimal \\
\hline $\mathrm{CFI}$ & 0.96 & $>0.90$ & Optimal \\
\hline
\end{tabular}

Table 4 shows that all the fit indices of the final path model, except for the significance of the chi-square test, have a good fit. Of course, given that the chi-square test is sensitive to the sample size, its significance is not so important. Therefore, the model drawn in Fig1 can be generalized to the general community.

\section{Discussion}

Adolescence is one of the most important stages in a person's life. This period can be called a period of storm and stress; this period has a wide range of conflicts and challenges. The present study is based on one of the common challenges of adolescence, which is bullying in schools. To address this issue in the present study, The Relationship between Difficulty in Emotion Regulation and Hostile attribution bias, Difficulty in Emotion Regulation and anger, Difficulty in Emotion Regulation and Alexithymia, Alexithymia with Hostile attribution bias, Alexithymia and anger and anger and Hostile attribution bias have been investigated. The results supported the significance of all relationships.

One of the significant paths was Difficulty in Emotion Regulation and Hostile attribution bias. The path coefficient for this relationship was 0.17 . This finding is consistent with the findings of Kawabata, Crick, \& Hamaguchi(52); Kokkinos et al(16). Explaining this finding, we can point out that hostile attribution bias plays an important role in the processing of various information. When information is ambiguous, the intent of others is Hostile attribution bias, which not only can lead to negative emotional reactions, but also facilitates negative emotions in ambiguous situations of hostile attribution and retrieving aggressive responses $(19,20)$. On the other hand, it is difficult to effectively regulate emotions, social adjustment and mental health(53). 
According to this study intentions, the Difficulty in Emotion Regulation and anger is one of the significant pathways, that the path coefficient for this relationship obtained equal to 0.22 . This finding is consistent with the results of research by Ersan(54), Garofalo et al(55) and Conway(39). In describing this finding can note to emotion disorder i.e. the ineffective use of strategies related to stress, depression, and aggressive behavior. Aggressive behaviors are referring to behaviors that are intended to harm or manipulate intentionally. People are strive to maintain, control, and enhance emotional experience to regulate emotions(16).

Another finding of the study showed a positive relationship between difficulty in emotion regulation and Alexithymia 0.09. This finding is consistent with the research of Pandey, Saxena and Dubai(31), Chen, Xu, Jing and Chan(44). Alexithymia is associated with persistent irregularities, and people with Alexithymia and Difficulty in Emotion Regulation have not proper function in recognizing the emotions of those people are around them, and they are characterized by reduced emotions as well as mastery of cognitive emotions(32).

According to obtained results in this study, there is positive relationship between Alexithymia and the Hostile attribution bias equal to 0.17 . The present finding is consistent with the research of Kafetsios and Hess(30), Hoffman et al(37) and Bergman et al(28). According to this finding people with Alexithymia have difficulty in emotion regulation and describing the inner and outer emotional emotions, this means that emotional cues are less noticeable. Thus, Alexithymia may reduce the tendency to emotions attention. Alexithymia has two emotional and cognitive components. The elements of the emotional component are the reduction of recognize and describe emotional feeling's ability and the expression of oneself and others experiences. Furthermore, the cognitive component of Alexithymia is characterized by low and weak introspective thinking(28).

Based on the findings of the present study, there is a positive relationship between alexithymia and anger that is 0.15 which is consistent with the studies of Velotti et al(56), Farah, Ling, Raine, Yang and Schug(15) and Sfeir, Geara, Hallit and Obeid(2). In expressing this finding, we can point out that alexithymia is a persistent trait that leads people to have difficulty in emotion regulation and describing feelings and emotions, and on the other hand, anger is an emotion that we experience in our daily lives and it is a different feeling from negative feelings. The presence of emotional resentment can play a significant role in highlighting this anger. $(17,56)$.

According to the results, there is a positive relationship between anger and bias in hostile attribution bias to 0.32 This finding is consistent with the research of Weeks et al(13), Kokkinos et al(16) and Van Bockstaele et al(20). The finding shows hostile attribution bias is seeming as a diagnostic stimulus that motivates people with anger and aggression problems make their behaviors vague and trigger defense mechanisms against people around them; and making hostile attribution bias as a secret process(57).

This study investigated the male adolescents bullying, and cannot be generalized to female adolescents. In this study, particular questionnaire was used to collect data. Therefore, the limitation of the research 
tool to the questionnaire is a limitation of the present study. These findings can be used as research support to enhance theoretical models related to psychological problems in adolescents and students.

It is recommended, studies can investigate the female adolescents bullying in schools, and in addition of a questionnaire, an interview can be used too; in this regard the results will be more accurate.

Furthermore, more adolescents can participate in future studies, so that the results can be generalized to larger communities.

\section{Conclusion}

Bullying is a widespread phenomenon that is considered as inappropriate and immoral behavior. The results of this study showed that adolescents who have more anger have more bullying than others. The results of this research can be used by school principals and officials. One of the applications derived from the results of the present study is to draw the attention of school psychologists to the bias of documents in bullying students. By holding educational and psychological courses for these students, the bias of documents in them can be changed and corrected. It is also possible to help students regulate their emotions by holding training courses or individual counseling so that they can better manage their behavior in angry situations. With such interventions, one can hope to reduce bullying in male students, which is one of the most common problems.

\section{Declarations}

\section{Ethics approval and consent to participate}

All participants gave informed written consent with the right to withdraw at any time. In the first part of the questionnaire, there was a paragraph introducing the study aim and assuring confidentiality of data by anonymous questionnaires. Participants did not experience any harm and they were allowed to stop their participation during the data collection process. The executive process of this research has been approved by the Ethics Committee of Kermanshah University of Medical Sciences under No. IR.KUMS.REC.1400.608.

\section{Consent for publication}

Not applicable

\section{Availability of data and materials}

The datasets during and/or analyzed during the current study available from the corresponding author on reasonable request.

\section{Competing interests}

The authors declare that they have no competing interests 


\section{Funding}

The authors received no specific funding for this work.

\section{Acknowledgements}

We sincerely thank all the participants and their families who participated in this study. We also thank the officials of the schools who cooperated well with us.

\section{Authors' Contributions}

MYA and PH conceived and designed the research; MYA collected, organized and analyzed the dada; $\mathrm{PH}$ and MYA wrote the paper. All authors read and approved the final manuscript.

\section{References}

1. Drzewiecki CM, Juraska JM. The structural reorganization of the prefrontal cortex during adolescence as a framework for vulnerability to the environment. Pharmacology Biochemistry and Behavior. 2020;199:173044.

2. Sfeir E, Geara C, Hallit S, Obeid S. Alexithymia, aggressive behavior and depression among Lebanese adolescents: A cross-sectional study. Child and Adolescent Psychiatry and Mental Health. 2020;14(1):32.

3. Simon KM, Harris SK, Shrier LA, Bukstein OG. Measurement-Based Care in the Treatment of Adolescents with Substance Use Disorders. Child and Adolescent Psychiatric Clinics. 2020;29(4):67590.

4. Baker $A E$, Galván A. Threat or thrill? the neural mechanisms underlying the development of anxiety and risk taking in adolescence. Developmental Cognitive Neuroscience. 2020;45:100841.

5. Hutson E, Melnyk B, Hensley V, Sinnott LT. Childhood Bullying: Screening and Intervening Practices of Pediatric Primary Care Providers. Journal of Pediatric Health Care. 2019;33(6):e39-e45.

6. Kennedy RS. Gender differences in outcomes of bullying prevention programs: A meta-analysis. Children and Youth Services Review. 2020;119:105506.

7. Bjereld $Y$, Augustine $L$, Thornberg R. Measuring the prevalence of peer bullying victimization: Review of studies from Sweden during 1993-2017. Children and Youth Services Review. 2020;119:105528.

8. Radoman M, Akinbo FD, Rospenda KM, Gorka SM. The impact of startle reactivity to unpredictable threat on the relation between bullying victimization and internalizing psychopathology. Journal of Psychiatric Research. 2019;119:7-13.

9. Rai A, Agarwal UA. Examining fit perceptions and workplace bullying relationship: The moderating role of power distance orientation. IIMB Management Review. 2020;32(4):365-75.

10. Liu Q-Q, Yang X-J, Hu Y-T, Zhang C-Y. Peer victimization, self-compassion, gender and adolescent mobile phone addiction: Unique and interactive effects. Children and Youth Services Review. 
2020;118:105397.

11. Austin L, Overton H, McKeever BW, Bortree D. Examining the rage donation trend: Applying the anger activism model to explore communication and donation behaviors. Public Relations Review. 2020;46(5):101981.

12. Berkout OV, Tinsley D, Flynn MK. A review of anger, hostility, and aggression from an ACT perspective. Journal of Contextual Behavioral Science. 2019;11:34-43.

13. Weeks BE, Kim DH, Hahn LB, DiehI TH, Kwak N. Hostile Media Perceptions in the Age of Social Media: Following Politicians, Emotions, and Perceptions of Media Bias. Journal of Broadcasting \& Electronic Media. 2019;63(3):374-92.

14. Robinson MD, Traurig E, Klein RJ. On looking versus leaping: A situated multilevel approach to trait anger and the anger-aggression relationship. Personality and Individual Differences. 2020;164:110130.

15. Farah T, Ling S, Raine A, Yang Y, Schug R. Alexithymia and reactive aggression: The role of the amygdala. Psychiatry Research: Neuroimaging. 2018;281:85-91.

16. Kokkinos CM, Karagianni K, Voulgaridou I. Relational aggression, big five and hostile attribution bias in adolescents. Journal of Applied Developmental Psychology. 2017;52:101-13.

17. Li X, Li B, Lu J, Jin L, Xue J, Che X. The relationship between alexithymia, hostile attribution bias, and aggression. Personality and Individual Differences. 2020;159:109869.

18. Gasse A, Kim WS, Gagnon J. Association between depression and hostile attribution bias in hostile and non-hostile individuals: An ERP study. Journal of Affective Disorders. 2020;276:1077-83.

19. Pabst A, Peyroux E, Rolland B, de Timary P, Maurage P. Hostile attributional bias in severe alcohol use disorder. Journal of Psychiatric Research. 2020;129:176-80.

20. Van Bockstaele B, van der Molen MJ, van Nieuwenhuijzen M, Salemink E. Modification of hostile attribution bias reduces self-reported reactive aggressive behavior in adolescents. Journal of Experimental Child Psychology. 2020;194:104811.

21. Nasby W, Hayden B, DePaulo BM. Attributional bias among aggressive boys to interpret unambiguous social stimuli as displays of hostility. Journal of Abnormal Psychology. 1980;89(3):459-68.

22. Schinckus L, Dangoisse F, Van den Broucke S, Mikolajczak M. When knowing is not enough: Emotional distress and depression reduce the positive effects of health literacy on diabetes selfmanagement. Patient Education and Counseling. 2018;101(2):324-30.

23. Zhang J, Hua Y, Xiu L, Oei TP, Hu P. Resting state frontal alpha asymmetry predicts emotion regulation difficulties in impulse control. Personality and Individual Differences. 2020;159:109870.

24. Ferrell EL, Watford TS, Braden A. Emotion regulation difficulties and impaired working memory interact to predict boredom emotional eating. Appetite. 2020;144:104450.

25. Charak R, Byllesby BM, Fowler JC, Sharp C, Elhai JD, Frueh BC. Assessment of the revised Difficulties in Emotion Regulation Scales among adolescents and adults with severe mental illness. Psychiatry 
Research. 2019;279:278-83.

26. Malesza M. Stress and delay discounting: The mediating role of difficulties in emotion regulation. Personality and Individual Differences. 2019;144:56-60.

27. Sifneos PE. The Prevalence of 'Alexithymic' Characteristics in Psychosomatic Patients. Psychotherapy and Psychosomatics. 1973;22(2-6):255-62.

28. Bergman MA, Vissers CTWM, Collard RM, van Eijndhoven P, Schene AH, Vrijsen JN. The Effect of Alexithymia on Attentional Bias Toward Emotional Stimuli in Depression: An Eye-Tracking Study. Frontiers in Psychiatry. 2021;11(1597).

29. Martínez-Sánchez F, Ato-García M, Adam EC, Huedo Medina TB, Selva España JJ. Stability in alexithymia levels: A longitudinal analysis on various emotional answers. Personality and Individual Differences. 1998;24(6):767-72.

30. Kafetsios K, Hess U. Seeing mixed emotions: Alexithymia, emotion perception bias, and quality in dyadic interactions. Personality and Individual Differences. 2019;137:80-5.

31. Pandey R, Saxena P, Dubey A. Emotion regulation difficulties in alexithymia and mental health. Europe's Journal of Psychology. 2011;7(4):604-23.

32. Sivathasan S, Fernandes TP, Burack JA, Quintin E-M. Emotion processing and autism spectrum disorder: A review of the relative contributions of alexithymia and verbal IQ. Research in Autism Spectrum Disorders. 2020;77:101608.

33. Choi EJ, Kim SJ, Kim HJ, Choi H-R, Lee S-A. Factors associated with alexithymia in adults with epilepsy. Epilepsy \& Behavior. 2021;114:107582.

34. Christopoulos AL, Poulios A, Pavlopoulos V. The relationship between dimensions of mental health and alexithymia in multiple sclerosis patients. Multiple Sclerosis and Related Disorders. 2020;46:102525.

35. Herman AM, Pilcher N, Duka T. Deter the emotions: Alexithymia, impulsivity and their relationship to binge drinking. Addictive Behaviors Reports. 2020;12:100308.

36. Lane RD. Alexithymia 3.0: reimagining alexithymia from a medical perspective. BioPsychoSocial Medicine. 2020;14(1):21.

37. Hoffmann F, Banzhaf C, Kanske P, Gärtner M, Bermpohl F, Singer T. Empathy in depression: egocentric and altercentric biases and the role of alexithymia. Journal of Affective Disorders. 2016;199:23-9.

38. Ellis A, MacLaren C. Rational emotive behavior therapy: A therapist's guide. Atascadero, CA, US: Impact Publishers; 1998. 166- p.

39. Conway AM. Girls, Aggression, and Emotion Regulation. American Journal of Orthopsychiatry. 2005;75(2):334-9.

40. Zhu W, Chen Y, Xia L-X. Childhood maltreatment and aggression: The mediating roles of hostile attribution bias and anger rumination. Personality and Individual Differences. 2020;162:110007. 
41. Gratz KL, Roemer L. Multidimensional Assessment of Emotion Regulation and Dysregulation: Development, Factor Structure, and Initial Validation of the Difficulties in Emotion Regulation Scale. Journal of Psychopathology and Behavioral Assessment. 2004;26(1):41-54.

42. Ghasemi h, Beyrami $m$, Vahedi s. The role of emotion regulation difficulty components in predicting academic procrastination. New Achievements in Humanities Studies. 2020;3(27):116-22.

43. Taylor GJ, Ryan D, Bagby RM. Toward the Development of a New Self-Report Alexithymia Scale. Psychotherapy and Psychosomatics. 1985;44(4):191-9.

44. Chen J, Xu T, Jing J, Chan RCK. Alexithymia and emotional regulation: A cluster analytical approach. BMC Psychiatry. 2011;11(1):33.

45. Ghorbani N, Sh Bagheri H. The effectiveness of Satyr short-term family therapy on alexithymia and emotional maturity in divorced couples. Journal of Assessment and Research in Counseling and Psychology. 2021;3(3):33-44.

46. Coccaro E, Noblett K, McCloskey M. Attributional and emotional responses to socially ambiguous cues: Validation of a new assessment of social/emotional information processing in healthy adults and impulsive aggressive patients. Journal of psychiatric research. 2009;43:915-25.

47. Wang Y, Cao S, Dong Y, Xia L-X. Hostile attribution bias and angry rumination: A longitudinal study of undergraduate students. Plos one. 2019;14(5):e0217759.

48. Brunner TM, Spielberger CD. State-Trait Anger Expression Inventory -2 child and adolescent (STAXI-2 C/A) professional manual. by Psychological Assessment Resources, inc (PAR). 2009.

49. Heidari Nasab I, Barabadi a, Moghaddasin m. The Study Factor Structure of a Persian Version of the State-Trait Anger Expression Inventory-2 Child and Adolescent (STAXI-2 C/A) in Iranian sample. Educational Measurement. 2015;6(20):1-29.

50. Tabachnick BG, Fidell LS, Ullman JB. Using multivariate statistics: Pearson Boston, MA; 2007.

51. Hu Lt, Bentler PM. Cutoff criteria for fit indexes in covariance structure analysis: Conventional criteria versus new alternatives. Structural Equation Modeling: A Multidisciplinary Journal. 1999;6(1):1-55.

52. Kawabata Y, Crick NR, Hamaguchi Y. The association of relational and physical victimization with hostile attribution bias, emotional distress, and depressive symptoms: A cross-cultural study. Asian Journal of Social Psychology. 2013;16(4):260-70.

53. Shaver PR, Mikulincer M. Adult attachment and emotion regulation. Handbook of emotion regulation, 2nd ed. New York, NY, US: The Guilford Press; 2014. p. 237-50.

54. Ersan C. Physical aggression, relational aggression and anger in preschool children: The mediating role of emotion regulation. The Journal of General Psychology. 2020;147(1):18-42.

55. Garofalo C, Velotti P, Zavattini GC. Emotion regulation and aggression: The incremental contribution of alexithymia, impulsivity, and emotion dysregulation facets. Psychology of Violence. 2018;8(4):470-83.

56. Velotti P, Garofalo C, Petrocchi C, Cavallo F, Popolo R, Dimaggio G. Alexithymia, emotion dysregulation, impulsivity and aggression: A multiple mediation model. Psychiatry Research. 
2016;237:296-303.

57. Hiemstra W, De Castro BO, Thomaes S. Reducing Aggressive Children's Hostile Attributions: A Cognitive Bias Modification Procedure. Cognitive Therapy and Research. 2019;43(2):387-98.

Figures

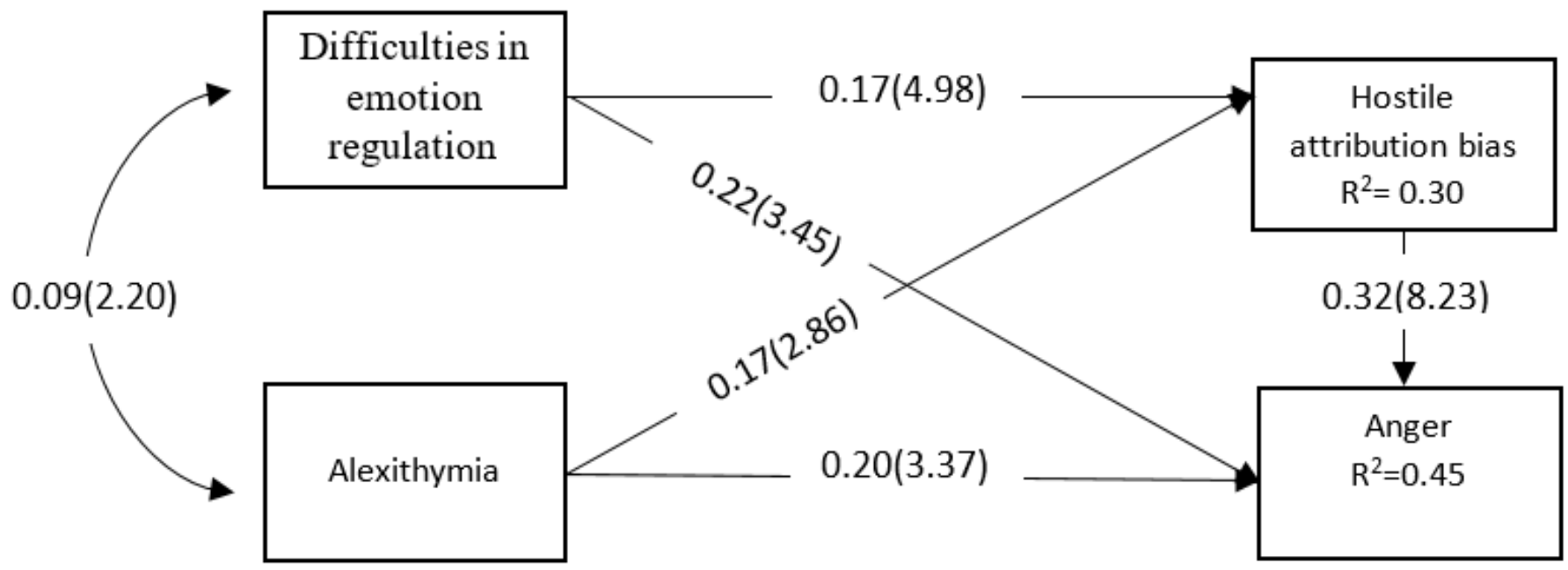

Figure 1

Path diagram for relationships between variables with standard parameter (and value $\mathrm{T}$ ) 